\title{
O GERENCIALISMO NA GESTÃO DA EDUCAÇÃO BÁSICA ESTADUAL DE MATO GROSSO/BRASIL
}

\author{
DOI: $10.5902 / 2318133831922$
}

\author{
Divino Batista Alves Rosa \\ Escola Estadual Rosa dos Ventos, Brasil.
}

\begin{abstract}
Resumo
Neste texto apresenta-se o influxo do gerencialismo na configuração da gestão da educação básica estadual pelo governo do Estado de Mato Grosso (2015/2018). Para tanto, utilizamos da revisão bibliográfica e análise de documentos. A influência da lógica do gerencialismo aparece na gestão da educação básica do Estado de Mato Grosso por meio de ações e programas, tais como a Avaliação Diagnóstica do Ensino Público Estadual de Mato Grosso - Adepe/MT -, teste estandardizado aplicado nos $2^{\circ}, 4^{\circ}, 6^{\circ}$ e $8^{\circ}$ ano do ensino fundamental, e no $1^{\circ}$ e $2^{\circ}$ anos do ensino médio, assim como na regulação do trabalho dos professores por meio da definição dos objetivos de aprendizagens inseridos no sistema de diário eletrônico.

Palavras-chave: gestão da educação; gerencialismo; teste estandardizado.
\end{abstract}

\section{THE MANAGERIALISM INFLUX IN THE MANAGEMENT OF THE STATE BASIC EDUCATION IN MATO GROSSO/BRAZIL}

\begin{abstract}
This paper presents the managerialism influx in the configuration of Basic Education by the Government of the State of Mato Grosso (2015/2018). Literature review, documental analysis and content analysis have been used. The influence of the managerialism logic has appeared in Basic Education in the State of Mato Grosso by means of actions and programs such as the Diagnostic Evaluation of Public Education of the State of Mato Grosso - Adepe/MT -, which is a standardized test applied to the $2^{\text {nd }}, 4^{\text {th }}, 6^{\text {th }}$ and $8^{\text {th }}$ grades of the Elementary School, and in the $1^{\text {st }}$ and $2^{\text {nd }}$ grades of the High School, as well as regulation of teacher work through the of learning goals inserted in the system of electronic diary.

Key-words: education management; managerialism; standardized test.
\end{abstract}




\section{Introdução}

N este trabalho apresentamos a influência dos conceitos da concepção da nova gestão pública nos programas e ações empreendidos pelo governo do Estado de Mato Grosso (2015-2018), por meio da Secretaria de Estado de Educação, Esporte e Lazer - Seduc/MT - no arranjo da gestão da educação básica estadual. Vale salientar que a nova gestão pública - NPM -, ou, de acordo com Abrucio (1997), o modelo gerencial, que se caracteriza por introduzir padrões da racionalidade de mercado na administração pública.

De acordo com Shiroma e Evangelista (2011) a concepção de políticas, programas e ações governamentais direcionadas a gestão da educação é influenciada por instituições multilaterais, como o Banco Interamericano de Desenvolvimento - BID - e o Banco Mundial - BM -, sobretudo os cognominados países de terceiro mundo, sob o argumento de que as instituições educacionais públicas não possuem capacidade gerencial e técnica para executar as reformas proposta, de tal modo que sugere que o setor público se apoie nos modelos de gestão utilizados pelo setor privado, o que os tornaria mais eficaz e ampliaria a margem de uso de recursos.

O influxo dessa lógica argumentativa pode ser observado na iniciativa do governo do Estado de Mato Grosso, por meio da Secretaria de Estado de Educação, Esporte e Lazer e a empresa MT Participações e Projetos S/A (MT-PAR), por meio do edital n. 001/2016 de procedimento de manifestação de interesse Seduc/MT - que estruturou os procedimentos a serem adotado na modelagem de parceria público-privada na modalidade concessão administrativa dos serviços não pedagógicas de 76 unidades escolares e 15 centros de formação e atualização dos profissionais da educação Cefapro.

Essa lógica gerencialista se manifesta na política de gestão da educação básica do Estado de Mato Grosso ainda por meio de ações e programas governamentais como: a Avaliação Diagnóstica do Ensino Público Estadual de Mato Grosso - Adepe/MT -, teste estandardizado aplicado nos $2^{\circ}, 4^{\circ}, 6^{\circ}$ e $8^{\circ}$ ano do ensino fundamental, e no $1^{\circ}$ e $2^{\circ}$ anos do ensino médio, assim como pela definição dos objetivos de aprendizagens de todas as disciplinas do ensino fundamental no módulo de gestão educacional do Sistema Integrado de Gestão Educacional - Sigeduca -, o que permite o monitoramento por parte da gestão central, via web, do desenvolvimento dos objetivos de aprendizagem por eles definidos. Ainda nesse contexto de influência, a Seduc/MT contratou uma empresa consultoria Falconi Educação - para capacitar os gestores escolares sob o argumento de desenvolver um modelo de gestão para resultados, por meio do emprego de novos métodos, técnicas e ferramentas na gestão escolar (Mato Grosso, 2016).

Vale salientar que a avaliação por objetivos remete a discussão do gerencialismo na perspectiva inglesa. Abrucio (1997), afirma que este se caracterizou pela procura precípua de corte de pessoal, redução de custos e desconsideração da política no arranjo administrativo do Estado, assim como pela responsabilização dos funcionários por terem objetivos claros a serem cumpridos, ou seja, na procura por eficiência a administração por objetivos, teve papel de destaque nessa conjuntura, isso porque tornava "possível uma avaliação de desempenho baseada na comparação entre os resultados obtidos e o que fora previamente determinado" (p. 17). 
Nota-se, desse modo, que as ações concebidas pelo Estado de Mato Grosso, por meio da Secretaria de Estado de Educação, Esporte e Lazer, expressam a influência do modelo gerencialista vinculados aos conceitos de accountability, gestão de qualidade total, eficácia, eficiência, quase-mercado, os quais são de acordo com Shiroma e Evangelista (2011), Lima (2012), Schneider e Nardi (2015), orientações vinculadas a nova gestão pública. Vale salientar que esse modelo ganhou força no Brasil a partir da década de 1990 e que no atual momento se recrudesce, com a ênfase na incorporação da lógica de mercado a partir da importação de modelos de gestão privada, fundamentados em resultados e produtos para o interior da administração estatal.

\section{Nova gestão pública e a educação}

As políticas educacionais, de acordo com Azevedo (2004), devem ser compreendidas como uma política social, de maneira que é exigida sua inserção de modo amplo no espaço teórico-analítico próprio das políticas públicas, que representam a materialidade da intervenção do Estado ou o Estado em ação.

Nesse sentido, ainda de acordo com Azevedo (2004), pensar as políticas educacionais, políticas públicas, em um plano mais geral e abstrato significa ter presente que sua concepção relaciona a estruturas de poder, dominação e conflitos, infiltrados por todo o tecido social e que se condensa no Estado, ou seja, é preciso considerar nas políticas públicas os recursos de poder presente no processo de suas definições.

Nesse sentido, abordar a influência da lógica gerencial, nova gestão pública, nas ações empreendidas pelo governo do Estado de Mato Grosso na gestão da educação pública estadual, manifesta a compreensão da educação como parte do arranjo social da formação social capitalista, pois como pondera Frigotto (2009), "a educação em suas concepções e as políticas e a gestão pública dos sistemas educacionais ganham compreensão quando tomadas como constituídas e constituintes das relações e dos interesses das classes fundamentais, frações de classe e grupos sociais" (Frigotto, 2009, p. 65).

Lima (2012), quando discute a subordinação da educação na "sociedade da aprendizagem" a lógica do mercado na atualidade, de tal modo que assevera que "o poder da educação e da aprendizagem, qualquer que ele seja, não é compreensível no esquecimento dos fenômenos de poder e de controle institucionalizado que sobre a educação e aprendizagem, de há muito, vêm conhecendo distintas formas de expressão" (p. 36).

Essa ponderação desenvolvida por Lima (2012), em que reforça a necessidade de não esquecer as influências dos fenômenos de poder sobre a educação manifesta a relevância do Estado no arranjo organizacional das políticas de gestão educacional na atual configuração social. Isso porque o Estado desempenha função de poder decisivo no processo de produção e reprodução da lógica do mercado, do capital.

A importância do Estado na produção e reprodução do arranjo social, formação social capitalista, pode ser notada por meio das discussões relacionadas ao seu papel ao longo dos tempos na definição da disposição das relações sociais de produção e de poder, assim como política e econômica. Essa relevância ganhou ênfase a partir da década de 1970, quando há no mundo um alvoroço no arranjo produtivo, por meio da introdução de meios considerados mais flexíveis na disposição da produção, como a 
influência das inovações comercial, tecnológica e organizacional dos setores da informação e, principalmente, do setor financeiro, bem como da flexibilização das relações de trabalho, mercado e produção.

O episódio da crise financeira da década de 1980, que fortaleceu a lógica flexível da produção e o arranjo do Estado fundamentado na lógica neoliberal, teve sua base na grande quantidade de fundos do setor financeiro sem o fluxo para investimentos na produção, o que ampliou a acumulação e resultou em inflação, desemprego, estagnação da economia, aumento do petróleo, o que alargou ainda mais a quantidade de excedente disponível para investimentos no setor produtivo Harvey (2011).

Diante essa situação uma reorganização nas funções do Estado foi produzida pelas relações sociais de produção e pelas relações de poder, em que ganhou relevância o princípio organizacional do capital financeiro, contrapondo-se ao modelo de produção dominante, baseado no capital industrial de viés fordista-taylorista, assim como ao Estado de bem-estar na Europa e ao New Deal nos Estados Unidos, uma vez que ao Estado foi imputada a responsabilidade pela crise financeira pela qual passava a formação social capitalista, com o mote da crise fiscal.

Nessa conjuntura o modelo da nova gestão pública ou, de acordo com Abrucio (1997), o modelo gerencial ganhou relevância. Isso porque, a lógica do modelo da nova gestão pública caracteriza-se por introduzir padrões da racionalidade de mercado na administração pública. Vale enfatizar que o processo de acumulação acontece por meio de um regime que

se apoia na flexibilidade dos processos de trabalho, dos mercados de trabalho, dos produtos e padrões de consumo. Caracteriza-se pelo surgimento de setores de produção inteiramente novos, novas maneiras de fornecimento de serviços financeiros, novos mercados e, sobretudo, taxas altamente intensificadas de inovação comercial, tecnológica e organizacional. A acumulação flexível envolve rápidas mudanças dos padrões do desenvolvimento desigual, tanto entre setores como entre regiões geográficas, criando, por exemplo, um vasto movimento no emprego chamado "setor de serviços", bem como conjuntos industriais completamente novos em regiões subdesenvolvidas [...] também envolve um novo movimento que chamarei de "compressão do espaço-tempo" no mundo capitalista - os horizontes temporais da tomada de decisões privada pública se estreitam, enquanto a comunicação via satélite e a queda dos custos de transporte possibilita cada vez mais a difusão imediata dessas decisões num espaço cada vez mais amplo e variado. (Harvey, 2012, p. 140).

Nessa conjuntura a educação, segundo Lima (2012), ganhou uma centralidade inédita, atribuindo-Ihe propriedades salvíficas, uma vez que estamos na chamada "sociedade da aprendizagem" e "sociedade cognitiva" que apela para a pedagogização dos problemas sociais e econômicos, um paradigma que responsabiliza e atomiza 0 indivíduo. Nesse cenário, por influência do "mundo das fabulações" é exigido que a educação

seja mais eficaz na criação das condições propícias à adaptação dos indivíduos ao mundo complexo e competitivo em que vivem, dotando-os das competências e habilidades necessárias à sua sobrevivência e, ainda, das qualificações e dos conhecimentos que permitirão a inovação 
científica, tecnológica e empresarial requerida pela "economia do conhecimento" e pela "sociedade da informação". A "aprendizagem ao longo da vida" é, por essa razão, definida como a "chave" que permitirá o acesso de cada um a esse mundo novo que, parcialmente, existe já, evitando que o indivíduo fique para trás, enclausurado nos seus limites, déficits e lacunas, sem horizontes e sem vantagens competitivas para progredir. (p.15)

Vale salientar que o argumento dominante para solucionar o contexto da crise constante no qual está envolto o arranjo social e o Estado é, de acordo com Abrucio (1997), a adoção do modelo gerencialista na conformação da administração pública, uma vez que a condição de crise existente é atribuída a ação do Estado. A partir desse diagnóstico foi adotado o mote da necessidade do corte de custos e de pessoal, aumento da eficiência e atuação mais flexível do aparato burocrático do Estado nos processos de suas reformas, ou seja, produzir e reproduzir um modelo de Estado fundamentado na lógica da produtividade existente no setor privado.

Esse cenário é manifesto no processo de reforma do Estado brasileiro, iniciado a partir dos anos 1990 quando foi atribuído ao Estado a principal causa da crise econômicosocial pelo qual passava. Segundo Bresser Pereira (1998), a crise era resultado do crescimento distorcido do Estado a partir da década de 1970 e ao processo de globalização, o que implicava a redução das taxas de crescimento econômico, a elevação das taxas de desemprego e o aumento da taxa de inflação.

Nessa conjuntura reformista, de acordo com Peroni (2003), as políticas educacionais foram instadas a desenvolver processos para atingir os princípios da eficiência e eficácia, por meio da lógica da descentralização, responsabilização e terceirização dos serviços. De igual modo, Hypólito (2010) assenta a configuração das políticas educacionais resultantes do processo de reforma do Estado brasileiro a partir da década de 1990, sob influência do neoliberalismo, afirmando que os incrementos do modelo de gestão de consecução das políticas educacionais na atualidade são todos

dedicados a formas regulativas do trabalho docente, do currículo e da gestão escolar. Nesse sentido, ações notadamente gerencialistas são apresentadas como solução para todos os problemas da educação pública, articuladas, como se sabe, a partir de pressupostos da eficiência, dos resultados, da avaliação e da competência. (p. 1339)

Nessa perspectiva, pensar as ações desenvolvidas pelo governo do Estado na gestão da educação básica do Estado de Mato Grosso e seus efeitos na gestão escolar, implica conceber a educação no bojo do desenvolvimento histórico, social, cultural, político e econômico. Ressaltando que, no contexto atual, o discurso hegemônico pauta toda compreensão do tecido social e sua sociabilidade a lógica do processo produtivo, do mercado, produzindo um contorno complexo entre as esferas pública e privada, o que remonta a ponderação empreendida por Dourado (2011), em que assevera a necessidade de não somente desenvolver uma demarcação entre as fronteiras público e privado por meio da natureza e caráter das instituições, mas de igual modo, dos processos de gestão, administração e regulação dos recursos financeiros. 


\section{Ações desenvolvidas pelo governo do Estado de Mato Grosso na gestão educacional}

O contexto contemporâneo é caracterizado pela influência da lógica do capital no arranjo social. Assim, as mudanças e reformas concebidas para o setor da educação trazem impregnadas, de acordo com Oliveira (2011), conceitos originários das teorias administrativas tais como, produtividade, eficácia, excelência e eficiência, ganhando força mecanismos de controle e responsabilização, por meio do desenvolvimento de processos avaliativos pautados em testes estandardizados, como o Sistema de Avaliação da Educação Básica e o Exame Nacional de Ensino Médio.

Nessa perspectiva houve, na década de 1990 a aprovação da lei n. 9.394/96 - Lei de Diretrizes e Bases da Educação Nacional, elaboração dos Parâmetros Curriculares Nacional para o ensino fundamental, entre outros, dando coerência ao processo de execução das ações reformistas. As leis e normas produzidas em Mato Grosso a partir dessa década, que manifesta a lógica reformista do âmbito nacional são expressas por meio das leis complementares 49/98 e 50/98, que regulamentam, respectivamente, o sistema de ensino e a carreira dos profissionais de educação, além da lei ordinária $\mathrm{n}$. 7.040/98, que trata da gestão democrática do ensino público e da autonomia da gestão escolar.

Nesse cenário a Seduc/MT implantou, em 1999, para enfrentar os problemas do Ensino Fundamental, como repetência e evasão escolar, os Ciclos de Formação, tendo como parâmetros as experiências piloto de 1996 do Ciclo Básico de Aprendizagem e o Projeto Terra, desenvolvido em 22 escolas estaduais urbanas e rurais e considerado exitoso.

O Estado de Mato Grosso, no período dos anos de 2008 a 2010, elaborou o documento, Orientações curriculares: concepções para a educação básica, que definiu as bases teórico-metodológicas de organização da educação básica do Estado de Mato Grosso. Ficou definido nesse documento que o Ensino Fundamental seria organizado em ciclos de formação humana, tendo como base para o planejamento do ensino as matrizes de capacidades das áreas de conhecimento, as quais são: Ciências Humanas, Linguagens, Ciências da Natureza e Matemática (Mato Grosso, 2010).

Os programas, ações e propostas defendidas pelo atual governo (2015-2018) se pautam no incremento de atos vinculados a dimensão administrativa e pedagógico. Nesse cenário, foi implantado o mecanismo de avaliação em larga escala, por meio da assessoria do Centro de Políticas Públicas e Avaliação da Educação da Universidade Federal de Juiz de Fora, o qual foi denominada de Avaliação Diagnóstica do Ensino Público Estadual de Mato Grosso - Adepe/MT -, teste estandardizado, aplicada nos 2o, $4^{\circ}$, $6^{\circ}$ e $8^{\circ}$ ano do ensino fundamental, e no $1^{\circ}$ e $2^{\circ}$ anos do ensino médio.

De igual modo foi implantada a definição dos objetivos de aprendizagens a serem trabalhados pelo conjunto das disciplinas no decorrer dos anos do ensino fundamental, ressaltando que esses objetivos foram concebidos pela Seduc sem a participação dos profissionais da educação. Vale salientar que o acompanhamento da execução desses objetivos de aprendizagem definidos pela Seduc, por parte dos professores, é feito por 
meio do diário eletrônico, que integra o módulo de Gestão Educacional do Sistema Integrado de Gestão Educacional - Sigeduca -, além do fato que servirão de base para as matrizes de referências no processo de elaboração da Adepe/MT, disciplinas de Língua Portuguesa e Matemática.

Ainda nesse cenário a Seduc/MT contratou uma empresa de consultoria - Falconi Educação - para capacitar os gestores escolares, diretores, sob o argumento de desenvolver um modelo de gestão para resultados, por meio do emprego de novos métodos, técnicas e ferramentas na gestão escolar (Mato Grosso, 2016).

Nesse contexto de ações voltadas a gestão educacional, o atual governo do Estado de Mato Grosso está em processo de implantação do sistema de parceria público-privada para a concessão administrativa de serviços considerados não pedagógicas de 76 unidades escolares e 15 centros de formação e atualização dos profissionais da educação.

Essa situação remete à reflexão desenvolvida por Dourado (2007), em que destaca a necessidade de conceber as políticas educacionais e gestão articuladas ao contexto mais amplo dos processos sociais, ultrapassando a dinâmica intraescolar, sem, contudo, negligenciar a importância social da escola, e dos processos relativos a cultura de sua organização e gestão. Ou seja, o autor pondera a necessidade de não "reduzir a análise das políticas e da gestão educacional à mera descrição dos seus processos de concepção ou de execução, importando, sobremaneira, apreendê-las no âmbito das relações sociais em que se forjam as condições para sua proposição e materialidade" (p. 922).

\section{Considerações finais}

Pôde-se notar a influência do princípio da nova gestão pública na concepção de ações e programas desenvolvidos pelo atual governo, salientando que a NPM concebe a gestão pública de acordo com Abrucio (1997) e Paula (2005) sob o viés da gestão de empresas, ou seja, a gestão privada, o que significa estar a gestão do Estado subordinada a influência dos princípios comportamentais do capital, ou seja, comprometido com a redução de custos, sobretudo em áreas sociais, vale destacar que a educação faz parte do rol das chamadas áreas sociais.

Essa lógica se manifesta no discurso e ações do governo em termos como eficiência, eficácia, efetividades, gestão para resultados, entre outros. Conceitos estes presentes na concepção de programas e ações voltados a dimensão pedagógica e administrativa das escolas como, a introdução do mecanismo estandardizado de avaliação por meio da Adepe/MT, definição dos objetivos de aprendizagens a serem trabalhados pelos professores no Ensino Fundamental registrados no diário eletrônico, além da proposta de implantação das parceiras público-privadas, para construção, reforma e gestão dos serviços não pedagógicos das unidades escolares, sob a justificativa de otimizar processos, previsibilidade de custos, divisão de responsabilidades, e sobretudo foco do setor público em sua atividade principal, ou seja, redução de custos em serviços, políticas sociais, com o mote da eficiência, gestão para resultados.

Esse cenário, portanto, exige que nos aprofundemos nas análises dos programas, ações e discursos desenvolvidos pelo governo do Estado de Mato Grosso, visto que não é objetivo desse trabalho fazer uma avaliação, quantitativa ou qualitativa, sobre a 
influência da lógica da nova gestão pública na concepção dos programas e ações desenvolvidos pelo Estado junto a educação básica estadual, mas apenas mostrar a influência dessa lógica na definição do arranjo administrativo estatal para a educação básica estadual.

\section{Referências}

ABRUCIO, Fernando Luiz. O impacto do modelo gerencial na administração pública: um breve estudo sobre a experiência internacional recente. Brasília: Enap, 1997.

APPLE, Michael. Para além da lógica do mercado: compreendendo e opondo-se ao neoliberalismo. Rio de Janeiro: DP\&A, 2005.

AZEVEDO, Janete Maria Lins. A educação como política pública. Campinas: Autores Associados, 2004.

AZEVEDO, Janete Maria Lins. O estado, a política educacional e a regulação do setor educação no Brasil: uma abordagem histórica. In: AGUIAR, Márcia Angela da S; FERREIRA, Naura Syria Carapeto (org.). Gestão da educação, impasses, perspectivas e compromisso. São Paulo: Cortez, 2011, p. 91-112.

BRASIL. Ministério da Educação. Lei de Diretrizes e Bases da Educação Nacional. Disponível <http://legislacao.planalto.gov.br/legisla/legislacao.nsf/Viw_Identificacao/lei\%209.3941996?OpenDocument>. Acesso em 14 jun. 2016.

BRASIL. Parâmetros curriculares nacionais: introdução aos parâmetros curriculares nacionais. Brasília: MEC/SEF, 1997.

BRESSER PEREIRA, Luís Carlos. A reforma do estado dos anos 90 lógica e mecanismos de controle. Lua Nova Revista de Cultura e Política, São Paulo, n. 45, 1998, p. 49-95.

DOURADO, Luiz Fernandes. Políticas e gestão da educação básica no Brasil: limites e perspectivas. Educação e sociedade, Campinas, v. 28, n. 100, 2016, p. 921-946.

DOURADO, Luiz Fernandes. O público e o privado na agenda educacional brasileira. In: In: AGUIAR, Márcia Angela da S; FERREIRA, Naura Syria Carapeto (org.). Gestão da educação, impasses, perspectivas e compromisso. São Paulo: Cortez, 2011, 45-86.

FRIGOTTO, Gaudêncio. Política e gestão educacional na contemporaneidade. In: FERREIRA, Eliza Bartolozzi; OLIVEIRA, Dalila Andrade (org.). Crise da escola e políticas educativas. Belo Horizonte: Autêntica, 2009, p. 35-57.

HARVEY, David. Condição pós-moderna. São Paulo: Loyola, 2012.

HARVEY, David. O enigma do capital: e as crises do capitalismo. São Paulo: Boitempo, 2011.

HYPOLITO, Álvaro Moreira. Políticas curriculares, estado e regulação. Educação e sociedade, Campinas, v. 31, n. 113, 2010, p. 1337-1354.

LIMA, Licínio C. Aprender para ganhar, conhecer para competir: sobre a subordinação da educação na sociedade da aprendizagem. São Paulo: Cortez, 2012.

MATO GROSSO. Governo de Mato Grosso. Seduc e consultoria Falconi Educação assinam contrato. Disponível em <http://www.mt.gov.br/-/3932867-seduc-e-consultoriafalconi-educacao-assinam-contrato>. Acesso em 9 maio 2016.

MATO GROSSO. Orientações curriculares: concepções para a educação básica. Cuiabá: Gráfica Print, 2010. 
MATO GROSSO. Edital n. 001/2016/ PMI-SEDUC/MT: Procedimento de manifestação de interesse. Cuiabá: SEDUC/MT-PAR, 2016. Disponível em <http://www.mtpar.mt.gov.br/\#!blank-2/t62bt>. Acesso em 10 maio 2016.

MATO GROSSO. Orientativo pedagógico 2016. Cuiabá: Seduc, 2016.

MORAES, R. Neoliberalismo: de onde vem para onde vai? São Paulo: Senac, 2001.

OLIVEIRA, D. A. A gestão democrática da educação no contexto da reforma do Estado. In: In: AGUIAR, Márcia Angela da S; FERREIRA, Naura Syria Carapeto (org.). Gestão da educação, impasses, perspectivas e compromisso. São Paulo: Cortez, 2011, p. 117-145.

PAULA, A. P. P. Administração pública brasileira entre o gerencialismo e a gestão social. RAE - Revista de Administração de Empresas, São Paulo, v. 45, n. 1, p.36-49, jan/mar. 2005. Disponível em: <http://www.scielo.br/pdf/rae/v45n1/v45n1a05.pdf>. Acesso em: 20 mai. 2016

PERONI, Vera. Política educacional e papel do Estado: no Brasil dos anos 1990. São Paulo: Xamã, 2003.

SANTOS, Milton. Por uma outra globalização: do pensamento único à consciência universal. Rio de Janeiro: Record, 2001.

SCHNEIDER, Marilda Pasqual; NARDI, Elton Luiz. Accountability em educação: mais regulação da qualidade ou apenas um estágio do Estado-avaliador? ETD - Educação Temática Digital, Campinas, v. 17, n. 1, 2015, p. 58-74. Disponível em $<$ http://periodicos.sbu.unicamp.br/ojs/index.php/etd/article/view/8634818>. Acesso em 23 mar. 2016.

SHIROMA, Eneida Oto et al. Política educacional. Rio de Janeiro: Lamparina, 2011.

VIEIRA, Evaldo Amaro. Os direitos e a política social. São Paulo: Cortez, 2009.

Divino Batista Alves Rosa é graduado em Geografia, mestre em educação, estudante do curso de doutorado em Geografia na Universidade Federal do Rio Grande do Sul, professor efetivo da educação básica da rede estadual de educação do Estado de Mato Grosso.

Endereço: Rua das Paineiras, 1400 - Sinop - MT - Brasil.

E-mail: divinobatista@gmail.com.

Recebido em 12 de maio de 2018.

Aceito em 7 de julho de 2018.

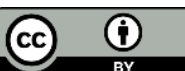

